\title{
CINZA DE BIOMASSA FLORESTAL: ALTERAÇÕES NOS ATRIBUTOS DE SOLOS ÁCIDOS DO PLANALTO CATARINENSE E EM PLANTAS DE EUCALIPTO
}

\section{ASH BIOMASS FOREST: ALTERATION IN THE ATRIBUTES OF ACID SOILS FROM SANTA CATARINA PLATEAU AND EUCALYPTUS PLANTS}

\author{
Franciani Rodrigues da SILVA ${ }^{1}$ \\ Jackson Adriano ALBUQUERQUE² \\ Luciano Colpo GATIBONI ${ }^{3}$ \\ Jacson Marcelo MARANGONI ${ }^{4}$
}

\begin{abstract}
RESUMO
No processo industrial de obtenção da celulose são gerados resíduos sólidos e líquidos, os quais necessitam alternativas viáveis para seu reaproveitamento. Este trabalho objetivou avaliar o efeito da aplicação de resíduos produzidos pelas indústrias de celulose e papel em plantas de eucaliptos em dois solos do planalto catarinense. $O$ experimento foi conduzido em Lages, SC, em casa de vegetação climatizada no Centro de Ciências Agroveterinárias da Universidade do Estado de Santa Catarina com um Cambissolo Húmico e um Nitossolo Háplico acondicionados em vasos de PVC com capacidade de $5 \mathrm{dm}^{3}$. O delineamento experimental utilizado foi inteiramente casualizado, com quatro repetições, contendo os seguintes tratamentos: Sem corretivo (Test); 3, 6, 12, 18 e $24 \mathrm{t} \mathrm{ha}^{-1}$ de cinza de biomassa florestal. Mudas de Eucalyptus viminalis com 60 dias de idade foram transplantadas nos vasos e cultivadas por 70 dias, quando foram avaliados os atributos químicos e físicos do solo, a massa seca produzida e a composição química da parte aérea das plantas de eucaliptos. As doses de cinza de biomassa florestal não alteraram os atributos físicos dos solos nem o pH, mas reduziu a saturação por $\mathrm{Al}$, elevou os teores de $\mathrm{K}, \mathrm{P}, \mathrm{Ca}, \mathrm{Mg}$ e a soma por bases dos solos. A cinza elevou do teor de $\mathrm{K}$ no tecido da parte aérea do eucalipto cultivado no Cambissolo e no Nitossolo, e do P no Nitossolo, mas os demais elementos e a produção de massa seca de eucalipto não foram alterados.
\end{abstract}

Palavras-chave: Resíduo industrial; celulose; eucalipto; produção de mudas.

\section{ABSTRACT}

The industrial process to obtain cellulose generates solid and liquid residues that need viable alternatives to its destination. This work was carried out to evaluate the effect of the application of residues of cellulose and paper industries in Eucalyptus plants on two soils from Santa Catarina plateau. The experiment was done in Lages, Santa Catarina state under greenhouse conditions at the Santa Catarina State University using a Humic Cambisol and a Haplic Nitosol packed in PVC pots with a capacity of $5 \mathrm{dm}^{3}$. The experimental design was completely randomized with four replicates. The treatments were: No corrective (Test); 3, 6, 12, 18 and $24 \mathrm{t} \mathrm{ha}^{-1}$ of forest biomass ash. Seedlings of Eucalyptus viminalis with 60 days of age were transplanted in the vases and cultivated by 70 days, when they were evaluated soil chemical and physical attributes, the plant dry mass and chemical composition of Eucalyptus shoot. The doses of forest biomass ash neither affect the soil physical attributes nor the soil pH, but it reduced the Al saturation, it elevated the content of $\mathrm{K}, \mathrm{P}, \mathrm{Ca}$, $\mathrm{Mg}$ and the sum for bases of the soils. The ash increased the content of $\mathrm{K}$ in the tissue of the shoots of Eucalyptus grown in the Cambisol and the Nitosol and P in the Nitosol, but the other elements and production of dry weight of eucalyptus have not changed.

Key-words: Industrial residues; cellulose; Eucalyptus; seedling production.

\footnotetext{
${ }^{1}$ Mestre em Manejo do Solo, Universidade do Estado de Santa Catarina, Centro de Ciências Agroveterinárias (UDESC), Lages, Santa Catarina, Brasil. E-mail: francianiagro@yahoo.com.br

2. Professor Departamento de Solos da Universidade do Estado de Santa Catarina (UDESC), Pesquisador do CNPq. Av. Luiz de Camões, 2090, Bairro Conta Dinheiro, Lages, Santa Catarina, Brasil, CEP: 88520-000. E-mail: albuquerque@pq.cnpq.br

${ }^{3}$ Professor Departamento de Solos da Universidade do Estado de Santa Catarina (UDESC), Lages, Santa Catarina, Brasil. Pesquisador do CNPq. E mail: gatiboni@cav.udesc.br

${ }^{4}$ Aluno do curso de Engenharia Florestal da Universidade do Estado de Santa Catarina (UDESC), Lages, Santa Catarina, Brasil. E-mail: jacsonlight@yahoo.com.br.
} 
SILVA, F.R. et al. Cinza de biomassa florestal: alterações nos atributos...

\section{INTRODUÇÃO}

No Brasil, com a crescente produção de papel e celulose e a busca pela qualidade dos produtos, as indústrias do setor têm gerado grandes quantidades de resíduos líquidos e sólidos. Aproximadamente $48 \mathrm{t}$ de resíduo são geradas para cada $100 \mathrm{t}$ de celulose produzida (Bellote et al., 1998). A maior parte dos resíduos sólidos gerados em indústrias de papel e celulose consiste em fibras que escapam do processo, além de sais inorgânicos, casca e fragmentos de madeira que são geralmente armazenados em depósitos próximos à indústria. Assim, define-se como resíduo, as sobras que ocorrem no processamento mecânico, físico ou químico, e que não são incorporadas ao produto final (Bellote et al., 1998). Os principais resíduos produzidos pelas indústrias de papel e celulose são: a casca da madeira, a lama de cal, o "dregs", o "grits", o lodo da estação de tratamento de esgoto, o lodo biológico, o resíduo celulósico e a cinza de caldeira resultante da queima de biomassa (Nolasco et al., 2000).

Alguns resíduos, como a lama de cal, o dregs, o grits e a cinza, contem nutrientes e podem ter poder corretivo da acidez como $\mathrm{CaO}, \mathrm{CaOH}$, $\mathrm{CaSiO}_{3}, \mathrm{NaOH}$, além de $\mathrm{CaCO}_{3}$ e $\mathrm{MgCO}_{3}$. Por isso são usados como fertilizantes e corretivos da acidez, sendo uma alternativa ao uso de calcário (Carvalho-Pupatto et al., 2004; Ramos et al., 2006).

A cinza produzida durante a queima da biomassa florestal possui em sua composição compostos orgânicos e inorgânicos que podem ter efeitos favoráveis para a planta, especialmente naqueles solos com maior deficiência nutricional (Jordan et al., 2002). Como a cinza de biomassa possui cátions como $\mathrm{K}, \mathrm{Ca}$ e $\mathrm{Mg}$, além de $\mathrm{P}$ e uma relação $\mathrm{C} / \mathrm{N}$ de $30 / 1$, esse resíduo tem potencial para uso em solos com plantios florestais para repor os nutrientes extraídos pelas árvores (Bellote et al., 1998).

O efeito benéfico da cinza usada como fertilizante de base no plantio da cultura e, principalmente, como fertilizante de cobertura, é resultado da lenta de solubilização dos macro e micronutrientes (Nolasco et al., 2000). Além de melhorar as propriedades químicas do solo, o uso desse resíduo pode ainda resolver problemas da indústria com a alocação deste material, o que favorece o sistema de beneficiamento (Prado et al., 2002).

TABELA 1 - Composição química e granulométrica do Cambissolo Húmico, e do Nitossolo Háplico da camada de 0 a $0,20 \mathrm{~m}$ de profundidade, em Lages, SC.

\begin{tabular}{|c|c|c|c|c|c|c|c|c|c|c|}
\hline \multirow{2}{*}{ Profundidade } & \multirow{2}{*}{$\mathrm{pH}_{(\mathrm{H} 20)}$} & \multicolumn{4}{|c|}{ Cátions trocáveis } & \multirow[t]{2}{*}{$\mathrm{P}^{(2)}$} & \multirow[t]{2}{*}{$\mathrm{MO}^{(3)}$} & \multirow[t]{2}{*}{ Areia } & \multirow[t]{2}{*}{ Silte } & \multirow[t]{2}{*}{ Argila } \\
\hline & & $\mathrm{Ca}^{(1)}$ & $\mathrm{Mg}^{(1)}$ & $\mathrm{Al}^{(1)}$ & $\mathrm{K}^{(2)}$ & & & & & \\
\hline -(m)--- & --1:1-- & -- & cm & $\begin{array}{l}\mathrm{dc}_{\mathrm{c}} \mathrm{dm}^{-3}- \\
\text { Cam }\end{array}$ & $\overline{\text { olo Húm }}$ & $\mathrm{mg} \mathrm{dm}^{-3}$ & ------- & $----g$ & & ----י- \\
\hline $0-0,20$ & $4,2^{(\mathrm{MB}) 4}$ & $1,1^{(\mathrm{B})}$ & $1,1^{(\mathrm{A})}$ & $\begin{array}{l}6,6^{(\mathrm{A})} \\
\quad \text { Nitc }\end{array}$ & $\begin{array}{l}0,5^{(\mathrm{MA})} \\
\text { lo Háplic }\end{array}$ & $3,2^{(\mathrm{MB})}$ & 28 & 352 & 301 & 342 \\
\hline $0-0,20$ & $5,0^{(\mathrm{MB})}$ & $0,6^{(\mathrm{B})}$ & $0,3^{(\mathrm{B})}$ & $5,0^{(\mathrm{A})}$ & $0,1^{(\mathrm{MB})}$ & $0,7^{(\mathrm{MB})}$ & 29 & 270 & 430 & 300 \\
\hline
\end{tabular}

${ }^{1}$ Extrator $\mathrm{KCl} 1 \mathrm{~mol} \mathrm{dm}^{-3} ;{ }^{2}$ Extrator Mehlich $1 ;{ }^{3} \mathrm{MO}=$ Matéria orgânica; ${ }^{4}$ Classificação conforme CQFS-RS/SC (2004), onde $\mathrm{MB}=$ muito baixo; $\mathrm{B}=$ baixo; $\mathrm{M}=$ médio; $\mathrm{A}=$ alto; $\mathrm{MA}=$ muito alto.
As possibilidades de utilização de cinza de biomassa florestal em solos destinados à produção de culturas florestais são consideradas promissoras, uma vez que, além da grande oferta, apresenta nutrientes essenciais às culturas em sua composição. No entanto, para identificar a potencialidade de uso agrícola e suas possíveis limitações, o uso desse resíduo em solo deve ser precedido da determinação da composição química do resíduo e do solo, (Albuquerque et al., 2002), pois quando aplicado em quantidades consideradas inadequadas, pode prejudicar o solo e o meio ambiente pelo desbalanço de nutrientes.

Assim, é necessário estudar maneiras seguras do uso da cinza de biomassa em áreas florestais, definindo seus efeitos sobre o solo e o desenvolvimento de culturas, bem como as doses adequadas para cada tipo de solo.

O objetivo geral deste trabalho foi avaliar o uso da cinza de biomassa florestal como fertilizante em dois solos (Cambissolo Húmico e Nitossolo Háplico), cultivados com Eucalyptus viminalis em casa de vegetação.

\section{MATERIAL E MÉTODOS}

O experimento foi conduzido em Lages, SC, em casa de vegetação climatizada no Centro de Ciências Agroveterinárias da Universidade do Estado de Santa Catarina - CAV-UDESC no período de maio a novembro de 2007.

Foram coletadas amostras de dois solos na camada de 0 a $0,2 \mathrm{~m}$, utilizados com campo nativo: um Cambissolo Húmico de textura franco argilosa derivado de siltitos da formação Rio do Rastro com mineralogia predominante a caulinita e em menor concentração mica, argilominerais 2:1 com e sem hidróxido entrecamadas e quartzo (Almeida et al., 1997); o outro é um Nitossolo Háplico de textura franco argilosa, originado da alteração do basalto da formação Serra Geral com predominância de caulinita e em menor concentração vermiculita com hidróxido de $\mathrm{Al}$ entrecamadas e óxidos de $\mathrm{Fe}$ e de $\mathrm{Al}$ (Almeida et al., 2000). Após a coleta, as amostras de solos foram destorroadas, peneiradas em malha de 8 $\mathrm{mm}$, e acondicionados $2 \mathrm{~kg}$ de solo em vasos de PVC com capacidade de $5 \mathrm{dm}^{3}$. Os principais atributos desses solos estão descritos na Tabela 1. 
SILVA, F.R. et al. Cinza de biomassa florestal: alterações nos atributos...

O delineamento experimental utilizado foi inteiramente casualizado, com quatro repetições, contendo os seguintes tratamentos: $0 ; 3,6,12,18$ e $24 \mathrm{t} \mathrm{ha}^{-1}$ de cinza de biomassa florestal. As doses foram definidas considerando os teores de Ca contidos na cinza de biomassa florestal (Tabela 2), e a quantidade de Ca contida em $1 \mathrm{t}$ de calcário (em média $240 \mathrm{~kg}$ de $\mathrm{Ca}$ ), sendo que o tratamento com $12 \mathrm{t} \mathrm{ha}^{-1}$ equivale à quantidade de $\mathrm{Ca}$ contida em $1 \mathrm{t}$ de calcário. Os tratamentos foram calculados tendo como base a existência de 2.000 $\mathrm{t} \mathrm{ha}^{-1}$ de solo por hectare na camada de $0-20 \mathrm{~cm} \mathrm{e}$, assim, para o tratamento $12 \mathrm{t} \mathrm{ha}^{-1}$, foram aplicadas $6,0 \mathrm{~g}$ de cinza por $\mathrm{kg}$ de solo. A cinza foi misturada com o solo, o qual tinha densidade próxima a $0,8 \mathrm{~g}$ $\mathrm{cm}^{-3}$ no momento do plantio das mudas A cinza foi coletada nos fornos das caldeiras de processamento da celulose e permaneceu nesses fornos por dois ou mais processos de queima do cavaco de casca de pinus, sendo denominada de cinza requeimada.

TABELA 2 - Análise química da cinza de biomassa florestal da indústria de papel e celulose, utilizada no experimento.

\begin{tabular}{|c|c|c|c|c|c|c|c|c|c|c|c|c|c|c|c|c|c|c|}
\hline $\mathrm{PN}^{(1)}$ & Umidade & $\mathrm{pH}$ & $\mathrm{C}^{(2)}$ & $\mathrm{N}^{(3)}$ & $\mathrm{P}$ & $\mathrm{K}$ & $\mathrm{Ca}$ & $\mathrm{Mg}$ & $S$ & $\mathrm{Fe}$ & $\mathrm{Mn}$ & $\mathrm{Cu}$ & $\mathrm{Zn}$ & $\mathrm{Na}$ & $\mathrm{Cd}$ & $\mathrm{Cr}$ & $\mathrm{Ni}$ & $\mathrm{Pb}$ \\
\hline$\%$ & & & & ----- & -... & $\mathrm{g} \mathrm{kg}$ & & & & & --- & & & - $r$ & $\mathrm{~g} \mathrm{~kg}$ & & & - \\
\hline 6,5 & 80 & 9,7 & 260 & 1,6 & 1,8 & 13 & 19 & 5,3 & 1 & 13 & 1,1 & 39 & 100 & 768 & 0,3 & 40 & 22 & 4 \\
\hline
\end{tabular}

${ }^{1} \mathrm{PN}=$ Poder de Neutralização (Tedesco et al., 1995); ${ }^{2} \mathrm{C}=$ Carbono; ${ }^{3}$ Teor de $\mathrm{N}$ determinado por Kjeldahl e os demais elementos por digestão em ácido nítrico e lidos por Espectroscopia de emissão óptica com plasma acoplado indutivamente (ICP-OES)

Após 90 dias de incubação da cinza, plantou-se em cada vaso uma muda de eucalipto com 60 dias de idade (Eucalyptus viminalis Labill.), proveniente de semente. Os vasos foram irrigados periodicamente. Após 70 dias do plantio, a parte aérea das plantas foi coletada e amostras de solo foram retiradas para caracterização física e química.

As amostras de solo foram secas em estufa a $60^{\circ} \mathrm{C}$, por $24 \mathrm{~h}$, destorroadas, moídas e passadas em peneira $(2 \mathrm{~mm})$, para determinação do $\mathrm{pH}$ em água, teores de $\mathrm{Ca}, \mathrm{Mg}$ e $\mathrm{Al}$ trocáveis, $\mathrm{K}$ e P extraível (Tedesco et al., 1995); a soma de bases (SB), saturação por $\mathrm{Al}(\mathrm{m})$ e CTC efetiva foram calculadas (EMBRAPA, 1997). O grau de floculação foi calculado através da determinação dos teores de argila total (AT) e argila natural (AN). A argila total foi obtida através da dispersão do solo em água e $\mathrm{NaOH}$ e a argila natural através da dispersão do solo somente em água, determinados pelo método da pipeta (Gee \& Bauder, 1986). A determinação da estabilidade de agregados foi realizada segundo o método de Kemper \& Chepil (1965) a partir de agregados com diâmetro entre 4,76 e $8,0 \mathrm{~mm}$, e os resultados foram expressos pelo diâmetro médio geométrico (DMG).

$O$ tecido vegetal (parte aérea) foi seco em estufa a $65^{\circ} \mathrm{C}$ até massa constante, determinandose a produção de massa seca da parte aérea. Após, moeu-se o material (parte aérea) em moinho de facas e o material vegetal foi submetido à digestão sulfúrica para extração do K e P do tecido (Tedesco et al., 1995), sendo o fósforo determinado por espectrofotometria do complexo fosfomolibdato e o potássio determinado por fotometria de emissão de chama (Tedesco et al., 1995). Para determinação de $\mathrm{Ca}$ e $\mathrm{Mg}$, calcinou-se o tecido vegetal em mufla (Jones Junior \& Case, 1990) e as concentrações de $\mathrm{Ca}$ e Mg no tecido foram quantificadas por espectrofotometria de absorção atômica (Tedesco et al., 1995).
Os resultados foram submetidos à análise de variância, através do programa de análises estatísticas SAS (STATISTICAL ANALYSES SYSTEM, 2002). O fator quantitativo (dose) foi analisado para cada solo através da equação de regressão, contrastando-as e usando-se o polinômio significativo de maior grau.

\section{RESULTADOS E DISCUSSÃO}

$\mathrm{O} \mathrm{pH}$ dos solos não foi alterado com a aplicação de doses crescentes de cinza de biomassa florestal, permanecendo na média de 4,1 no Cambissolo e 4,4 no Nitossolo, contrariando resultados obtidos por alguns autores (Prado et al., 2002; Jordan \& Rodriguez, 2004). A aplicação de cinza não foi efetiva na neutralização da acidez do solo pelo fato desse resíduo apresentar baixo poder de neutralização $(6,5 \%)$ (Tabela 2$)$, já que é uma cinza requeimada. Como os solos utilizados são de elevada acidez potencial, devido aos altos teores de argila e matéria orgânica, já era esperado pouco efeito neutralizante da acidez pela cinza de biomassa, pois a quantidade de corretivos da acidez necessária nestes solos é alta, fazendo com que pequenas adições de um material com pouco poder neutralizante tenha pouco reflexo na diminuição da acidez ativa, em função do alto poder tampão do solo.

Embora não tenha havido diferença estatística entre os valores de $\mathrm{pH}$ dos solos observou-se decréscimo nos teores de Al trocável no Cambissolo e no Nitossolo com o aumento da dose de cinza de biomassa florestal (Figura 1). Esta redução foi linear para ambos os solos, sendo as magnitudes diferentes devido ao teor de $\mathrm{Al}$ do Cambissolo ser maior do que no Nitossolo (Tabela 1). Entretanto, mesmo com as altas doses aplicadas (24 t ha ${ }^{1}$ ), os teores de Al, estimados pela análise de regressão, ainda se mantiveram elevados (3,3 $\mathrm{cmol}_{\mathrm{c}} \mathrm{kg}^{-1}$ no Nitossolo e $5,5 \mathrm{cmol}_{\mathrm{c}} \mathrm{kg}^{-1}$ no Cambissolo). A saturação por alumínio, estimada 
SILVA, F.R. et al. Cinza de biomassa florestal: alterações nos atributos...

pela análise de regressão, diminuiu de $82 \%$ para $56 \%$ no Cambissolo e de $70 \%$ para $59 \%$ no Nitossolo, respectivamente na dose zero em comparação com a dose com $24 \mathrm{t}$ ha ${ }^{1}$ de cinza
(Figura 2). Em ambos os solos a saturação por alumínio ficou acima do valor considerado crítico para o desenvolvimento das culturas (CQFS-RS/ SC, 2004).
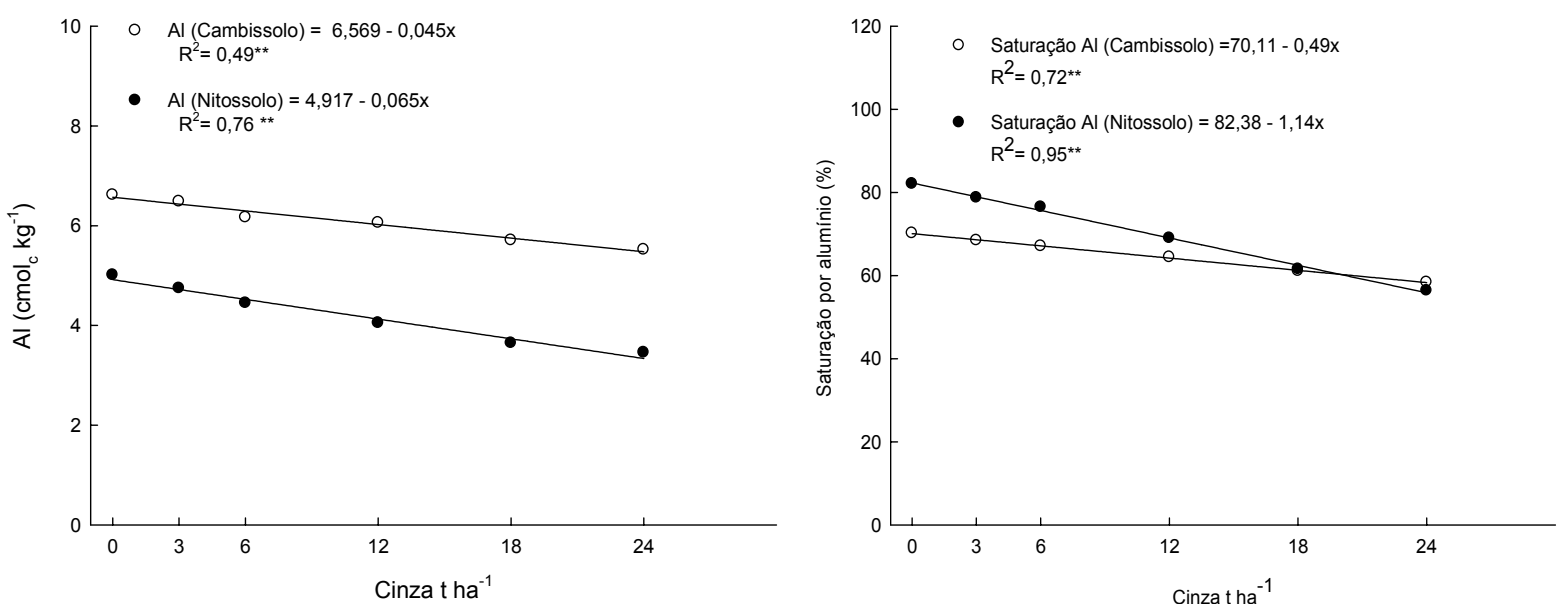

FIGURA 1 - Teores de alumínio $\mathrm{Al}^{+3}$ trocável e saturação por alumínio de um Cambissolo Húmico e Nitossolo Háplico submetidos a doses crescentes de cinza de biomassa florestal, em Lages-SC. Utilizouse o teste $\mathrm{F}$ para indicar a significância das regressões ( ${ }^{* *}$ significativo a $1 \%$ de probabilidade).

Devido à ausência de correção da acidez pela cinza de biomassa, não houve alteração da capacidade de troca de cátions efetiva (CTCe) em ambos os solos, sendo que a média da CTCe foi de 9,2 e 6,0 $\mathrm{cmol}_{\mathrm{c}} \mathrm{kg}^{-1}$ para o Cambissolo e o Nitossolo respectivamente. Isso possivelmente pode ser explicado devido a não alteração das cargas dependentes de $\mathrm{pH}$, ocorrendo apenas troca do Al adsorvido à superfície das partículas por outros cátions presentes na cinza.

A adição de cinza de biomassa florestal aumentou os teores trocáveis de $\mathrm{Ca}, \mathrm{Mg}, \mathrm{K}$ e a soma de bases nos dois solos (Figura 2), semelhante ao observado por Moro \& Gonçalves (1995). Já os teores de $\mathrm{P}$ disponível aumentaram de forma linear no Nitossolo, e no Cambissolo aumentaram até a dose de $18 \mathrm{t}$ ha de cinza, com posterior diminuição.

A cinza aumentou linearmente a concentração de $\mathrm{Ca}$ de $1,1 \mathrm{cmol}_{\mathrm{c}} \mathrm{kg}^{-1}$ na testemunha para $1,4 \mathrm{cmol}_{\mathrm{c}} \mathrm{kg}^{-1}$ na maior dose $(24 \mathrm{t}$ ha $^{-1}$ de cinza) no Cambissolo e de 0,7 para 1,3 $\mathrm{cmol}_{\mathrm{c}} \mathrm{kg}^{-1}$ no Nitossolo (Figura 2). Todavia, mesmo com aumento dos teores de $\mathrm{Ca}$ nos solos com a aplição da cinza, estes ficaram abaixo do nível crítico no solo que é de $2 \mathrm{cmol}_{\mathrm{C}} \mathrm{kg}^{-1}$ (CQFS-RS/SC, 2004). Efeitos semelhantes ao $\mathrm{Ca}$ foram observados para o Mg (Figura 2). No Cambissolo, os teores de $\mathrm{Mg}$ variaram de $1,1 \mathrm{cmol}_{\mathrm{c}} \mathrm{kg}^{-1} \mathrm{na}$ testemunha para $1,5 \mathrm{cmol}_{\mathrm{c}} \mathrm{kg}^{-1}$ na maior dose de cinza, teores considerados altos (CQFS-RS/SC, 2004). Todavia, no Nitossolo os teores de $\mathrm{Mg}$ ficaram abaixo do nível crítico de $0,5 \mathrm{cmol}_{\mathrm{c}} \mathrm{kg}^{-1}$ (CQFS-RS/SC, 2004), com exceção do tratamento que recebeu a maior dose de cinza $\left(24 \mathrm{t} \mathrm{ha}^{-1}\right)$.

Também para o $\mathrm{K}$ houve aumento linear, de $0,5 \mathrm{cmol}_{\mathrm{c}} \mathrm{kg}^{-1}$ para $1 \mathrm{cmol}_{\mathrm{c}} \mathrm{kg}^{-1}$ no Cambissolo e de $0,2 \mathrm{cmol}_{\mathrm{c}} \mathrm{kg}^{-1}$ para $0,6 \mathrm{cmol}_{\mathrm{c}} \mathrm{kg}^{-1}$ no Nitossolo, respectivamente na testemunha e na maior dose de cinza (Figura 2). No Cambissolo, em todos os tratamentos, o teor de $\mathrm{K}$ foi alto e, para $\mathrm{o}$ Nitossolo, a adição de $3 \mathrm{t} \mathrm{ha}^{-1}$ de cinza aumentou o teor de $\mathrm{K}$ para o nível médio e, com adições acima de $18 \mathrm{tha}^{-1}$, para acima do nível considerado alto (CQFS-RS/SC, 2004).

A principal peculiaridade dos solos do Planalto de Lages, como o Cambissolo e o Nitossolo, são a baixa soma de bases, reação fortemente ácida e altos teores de Al trocável (Almeida et al., 1997). Em ambos os solos, há predomínio de caulinita bem cristalizada, vermiculitas com hidróxi Al entrecamadas em quantidades menores e óxidos de ferro como a goethita e hematita (Almeida et al., 2000). Sendo assim, a cinza teria reduzida influência no aumento de $P$ no solo, devido à grande adsorção e fixação do elemento nos minerais do solo. Entretanto, observaram-se aumentos dos teores de $\mathrm{P}$ principalmente no Cambissolo, de $4,5 \mathrm{mg} \mathrm{kg}^{-1}$ na testemunha, para $49 \mathrm{mg} \mathrm{kg}^{-1}$ na maior dose de cinza (Figura 2). Para o Nitossolo, o aumento ocorreu em menor magnitude, de $0,7 \mathrm{mg} \mathrm{kg}^{-1}$ na testemunha para $6,2 \mathrm{mg} \mathrm{kg}^{-1}$ com a adição de $24 \mathrm{t}$ $\mathrm{ha}^{-1}$ de cinza. Sendo assim, é importante observar a capacidade da cinza em fornecer e aumentar os teores de $\mathrm{P}$ no solo, principalmente nas maiores dosagens de cinza. 
SILVA, F.R. et al. Cinza de biomassa florestal: alterações nos atributos...
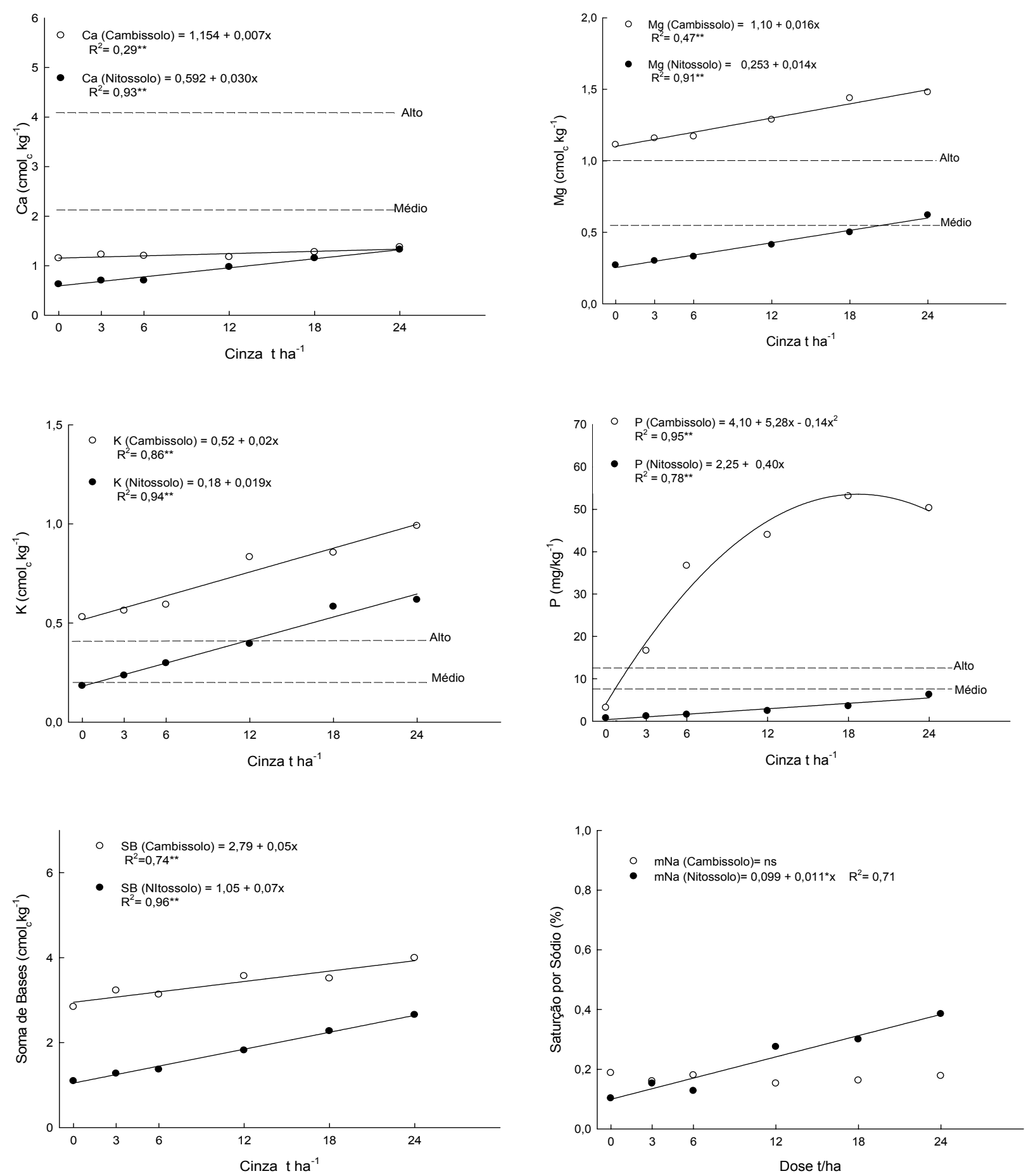

FIGURA 2 - Teores de cálcio, magnésio, potássio trocáveis, fósforo disponível, soma de bases (SB) e saturação por sódio ( $\mathrm{mNa}$ ) de um Cambissolo Húmico e Nitossolo Háplico submetidos a doses crescentes de cinza de biomassa florestal, em Lages-SC, com as respectivas faixas de suficiência nutricional no solo conforme a CQFS-RS/SC (2004). Utilizou-se o teste F para indicar a significância das regressões ( ${ }^{* *}$ significativo a $1 \%$ de probabilidade). 
SILVA, F.R. et al. Cinza de biomassa florestal: alterações nos atributos...

Com a adição de cinza de biomassa florestal, houve aumento dos cátions no solo, $\mathrm{Ca}^{+2}$, $\mathrm{Mg}^{+2} \mathrm{e} \mathrm{K}^{+}$; consequentemente,ocorreu aumento da soma de bases (Figura 2). Portanto a adição de cinza contribuiu para melhoria da qualidade química do solo.

A adição de doses crescentes de cinza de biomassa florestal não alterou significativamente a estabilidade dos agregados dos solos, sendo que a média, tanto no Cambissolo como no Nitossolo, o DMG foi de $5 \mathrm{~mm}$. Isso indica que a adição do resíduo não alterou a agregação do solo, possivelmente porque ele contém íons $\mathrm{Ca}^{+2}$ e $\mathrm{Mg}^{+2}$, que são cátions que auxiliam na agregação do solo. O efeito das doses de cinza sobre o grau de floculação da argila não foi significativo para ambos os solos, sendo que no Cambissolo a média foi de $90 \%$ com desvio padrão de 3,3 , e no Nitossolo de $80 \%$ com desvio padrão de 5,6. Devido à presença de sódio na constituição da cinza de biomassa florestal, esperava-se alterações nas propriedades físicas dos solos, principalmente no tratamento com maior dose da cinza. No entanto, a saturação por sódio foi alterada apenas no Nitossolo (Figura 2) e em pequena magnitude, pois nele a adição de doses crescentes de cinza de biomassa promoveram a elevação da saturação por sódio, aumento de $0,011 \%$ por tonelada de cinza aplicada, ocasionando uma saturação da CTC por $\mathrm{Na}$ em $0,36 \%$ para a maior dose. Este resultado demonstra a viabilidade da adição de cinza de biomassa florestal para os solos testados, quando se analisa apenas saturação por sódio como um fator limitante de uso. Lunardi et al. (2008) também observaram que a adição de resíduo proveniente da indústria de celulose, rico em $\mathrm{Na}$, não alterou a argila natural e a estabilidade de agregados em um solo reconstruído após mineração de carvão à céu aberto.

Apesar de alterar os cátions trocáveis e o $\mathrm{P}$ disponível, a cinza de biomassa não modificou a produção de massa seca da parte aérea das plantas de eucalipto aos 70 dias, o que contrasta com os resultados encontrados por Bellote et. al. (1998), que observaram uma tendência linear de incremento em produtividade de Eucalyptus grandis até as doses de $50 \mathrm{t} \mathrm{ha}^{-1}$ de cinza de biomassa. No Cambissolo a massa seca média da parte aérea foi de $11,75 \mathrm{~g}_{\text {planta }}{ }^{-1}$ e no Nitossolo 8,96 g planta $^{-1}$. A ausência de efeitos significativos na produção de massa seca pode ser atribuída ao curto período de incubação do experimento associado à baixa taxa de decomposição da cinza e às restrições químicas do Cambissolo e do Nitossolo (Tabela 1), além da grande exigência nutricional do eucalipto (CQFS-RS/SC, 2004). Nos dois solos, seguindo a classificação sugerida pela CQFS-RS/SC (2004), o pH é muito ácido, o teor de Ca muito baixo e o de Al muito elevado. Além disso, no Nitossolo são baixos os teores de $\mathrm{Mg}, \mathrm{K}$ e P (Tabela 1).

Apesar das mudanças nos teores de $\mathrm{Ca}$ e $\mathrm{Mg}$ no solo, a análise do tecido não detectou alterações na concentração destes elementos, o que pode ser devido ao tempo insuficiente para a ocorrência da mineralização, com lenta disponibilização desses elementos ao solo para posterior absorção dos nutrientes constituintes da cinza, ou devido a reduzida quantidade destes elementos contidos na cinza (Tabela 2). Porém, a adição de doses crescentes de cinza de biomassa aumentou os teores de $\mathrm{K}$ nos tecidos vegetais até a dose de $12 \mathrm{t} \mathrm{ha}^{-1}$ de cinza, sendo que nas doses maiores ocorreu diminuição desses teores (Figura 3) nos dois solos avaliados, o que pode ter ocorrido em função da diminuição da atividade de potássio na solução quando do aumento dos teores de cálcio e magnésio (Raij, 1991). A adição de cinza não modificou os teores de $\mathrm{P}$ no tecido do eucalipto no Cambissolo, já que este solo estava com teores dentro da faixa de suficiência na dose zero (CQFS-RS/SC, 2004). O Nitossolo por ser um solo naturalmente com baixa disponibilidade de fósforo (Tabela 1), apresentou elevação dos teores de fósforo com adição de cinza, para nível acima do nível crítico.

\section{CONCLUSÕES}

$A$ adição de cinza de biomassa florestal aumentou os teores de $\mathrm{Ca}, \mathrm{Mg}, \mathrm{K}, \mathrm{P}$, e a soma de bases, e diminuiu a saturação por $\mathrm{Al}$ no Cambissolo Húmico e no Nitossolo Háplico, mas não alterou o $\mathrm{pH}$ e os atributos físicos dos solos (grau de floculação e a estabilidade de agregados).

Devido à adição de cinza de biomassa florestal, houve aumento dos teores de $\mathrm{K}$ no tecido vegetal do eucalipto cultivado no Cambissolo e no Nitossolo e do $P$ no Nitossolo, porém não aumentaram os teores de $\mathrm{Ca}$ e $\mathrm{Mg}$ nos tecidos vegetais (parte aérea) nem a produção de massa seca da parte aérea das plantas de eucalipto.

\section{AGRADECIMENTOS}

À FAPESC pelo apoio ao financiamento da pesquisa e ao $\mathrm{CNPq}$ pela concessão de bolsa de estudo e de produtividade. 

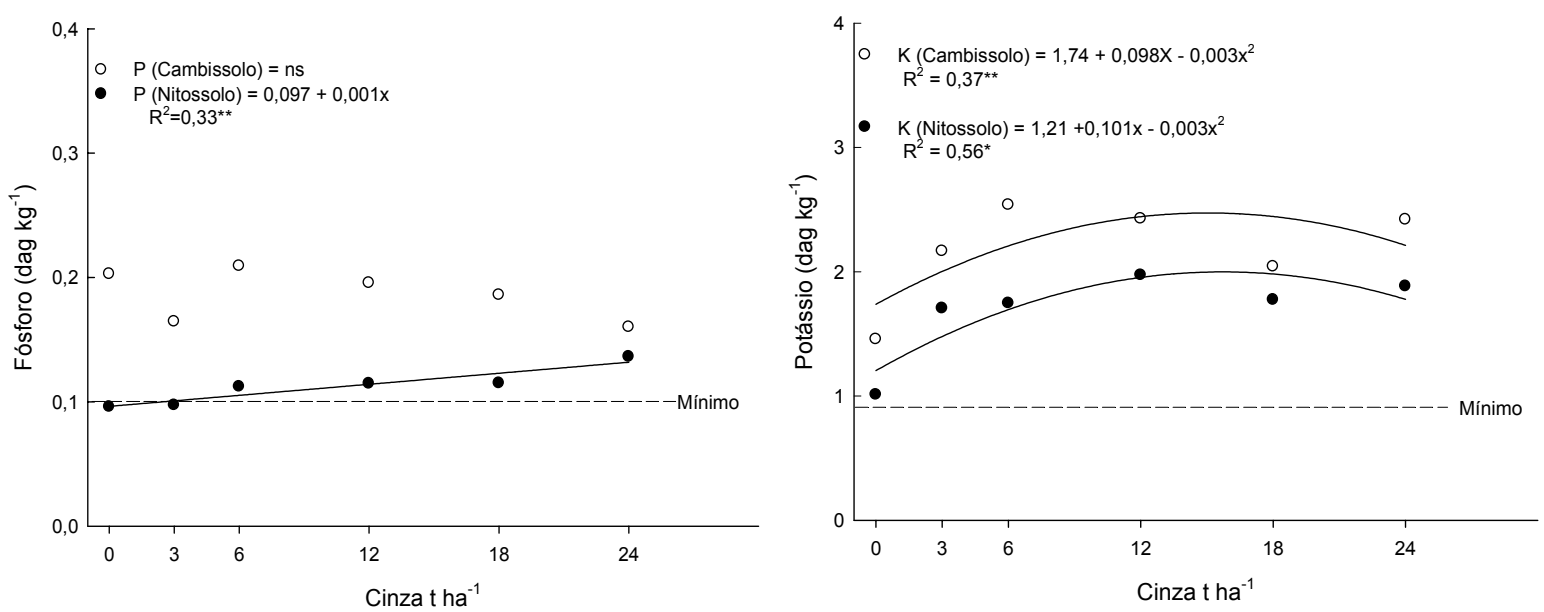

FIGURA 3 - Teores de e fósforo e potássio de plantas (parte aérea) de eucalipto cultivadas em um Cambissolo Húmico e Nitossolo Háplico submetidos a doses crescentes de cinza de biomassa florestal em Lages-SC, com o respectivo limite mínimo de suficiência no tecido foliar de eucalipto conforme a CQFS-RS/SC (2004). Utilizou-se o teste F para indicar a significância das regressões $\left({ }^{*} \mathrm{e}^{* *}\right.$ significativo a 5 e $1 \%$ de probabilidade).

\section{REFERÊNCIAS}

1. ALBUQUERQUE, J. A. et al. Propriedades físicas e químicas de solos incubados com resíduo alcalino da indústria de celulose. Revista Brasileira de Ciência do Solo, v. 26, n. 4, p.1065-1073, 2002.

2. ALMEIDA, J. A. et al. Caracterização mineralógica de Cambissolos originados de rohas pelíticas nos patamares do alto rio Itajaí e no planalto de Lages (SC). Revista Brasileira de Ciência do Solo, v. 21, n. 2, p.181-190,1997.

3. ALMEIDA, J. A. et al. Mineralogia da fração argila de solos vermelhos com horizontes superficiais brunados do planalto de Lages (SC). Revista Brasileira de Ciência do Solo, v. 24, n. 4, p.815-828, 2000

4. BELLOTE, A. F. J. et al. Resíduos da indústria de celulose em plantios florestais. Boletim de Pesquisa Florestal, v. 37 , p. 99-106, 1998.

5. CARVALHO-PUPATTO, J. G.; BÜLL, L. T.; CRUSCIOL, C. A. C. Atributos químicos do solo, crescimento radicular e produtividade do arroz de acordo com a aplicação de escórias. Pesquisa Agropecuária Brasileira, v. 39, n. 12, p. 1213$1218,2004$.

6. COMISSÃO DE QUÍMICA E FERTILIDADE DO SOLO - RIO GRANDE DO SUL/SANTA CATARINA (CQFS-RS/SC). Manual de adubação e de calagem para os estados do Rio Grande do Sul e de Santa Catarina. 10. ed. Porto Alegre: Sociedade Brasileira de Ciência do Solo/ Núcleo Regional Sul, 2004. 394 p.

7. EMPRESA BRASILEIRA DE PESQUISA AGROPECUÁRIA (EMBRAPA). Manual e métodos de análise do solo. 2. ed. Rio de Janeiro: Embrapa/CNPS, 1997. 212 p.

8. GEE, G. W.; BAUDER, J. W. Particle-size analysis. In: KLUTE, A. (Ed.) Methods of soil analysis. Part 1. Physical and mineralogical methods. 2. ed. Madison: American Society of Agronomy, 1986. p. 383-411.

9. JONES JUNIOR., J. B.; CASE, V. W. Sampling handling and analyzing plant tissue samples. In: WESTERMAN, R. L. (Ed.) Soil testing and plant analysis. Madison: Soil Science Society of America, 1990. p. 389-427 (SSSA Book Series, 3).

10. JORDAN, M. et al. Kraft mill residues effects on Monterey Pine growth and soil microbial activity. Environmental Quality, v. 31, n. 3, p. 1004-1009, 2002.

11. JORDAN, M; RODRIGUEZ, E. Effect of solid residues from the cellulose industry on plant growth. Journal of Plant Nutrition and Soil Science, v. 167, n. 3, p. 351-356, 2004.

12. KEMPER, W. D.; CHEPIL, W. S. Size distribution of aggregates. In: BLACK, C. A. et al. (Ed.) Methods of soil analysis. Part 1. Physical and mineralogical methods. 1. ed. Madison: American Society of Agronomy, 1965. p. 499-510.

13. LUNARDI, A. et al. Atributos físicos do solo em área de mineração de carvão influenciados pela correção da acidez, adubação orgânica e revegetação. Revista Brasileira de Ciência do Solo, v. 32, n. 4, p. 1379-1388, 2008.

14. MORO, L.; GONÇALVES, J. L. M. Efeitos da "cinza" de biomassa florestal sobre a produtividade de povoamentos puros de Eucalyptus grandis e avaliação financeira. IPEF, v. 48/49, p.18-27, 1995.

15. NOLASCO, A. M.; GUERRINI, I. A.; BENEDETTI, V. Uso de resíduos urbanos e industriais como fonte de nutrientes e condicionadores de solos florestais. In: GONÇALVES, J. L. M.; BENEDETTI, V. (Org.) Nutrição e fertilização florestal 1. ed. Piracicaba: IPEF. 2000, p. 385-414.

16. PRADO, R. M. et al. Efeito da cinza da indústria de cerâmica no solo e na nutrição de mudas de goiabeira. Acta Scientiarum, v. 24, p. 1493-1500, 2002

17. RAIJ, B. V. Fertilidade do solo e Adubação. São Paulo: Ceres, 1991. 343 p.

18. RAMOS, L. A. et al. Reatividade de corretivos da acidez e condicionadores de solo em colunas de lixiviação. Revista Brasileira de Ciência do Solo, v. 30, n. 5, p. 849-857, 2006. 
SILVA, F.R. et al. Cinza de biomassa florestal: alterações nos atributos...

19. STATISTICAL ANALYSIS SYSTEM (SAS). Statistical analysis system- getting started with the SAS learning edition, Cary: SAS Institute Inc., 2002. 86 p.

20. TEDESCO, M. J. et al. Análises de solo, plantas e outros materiais. 2. ed. Porto Alegre: Universidade Federal do Rio Grande do Sul, 1995. 174 p.

Recebido em 16/12/2008 Aceito em 30/07/2009 